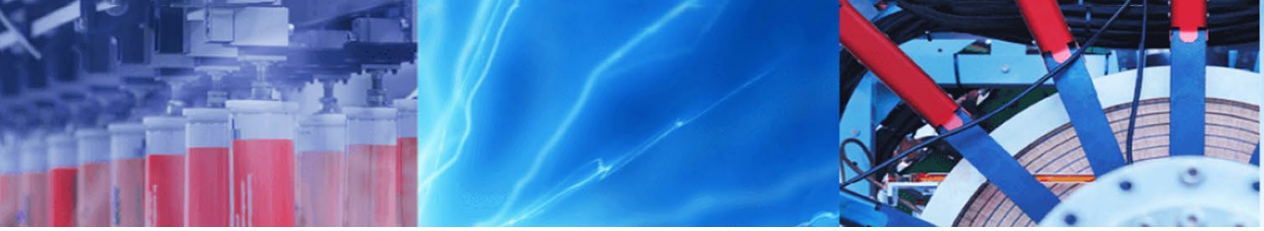

Research Article

\title{
Paints analysis and conservation treatment of painted sculpture: Jean Dubuffet, Guard Dog II
}

\author{
Ye Bin $\mathrm{Han}^{1} \cdot$ Na Ra Lee ${ }^{1}$. Young Mok Kim ${ }^{1}$. Jeong Ah Shin ${ }^{1} \cdot$ Sun Min Cha ${ }^{1} \cdot$ Hee Hong Kwon ${ }^{1}$
}

Received: 26 May 2021 / Accepted: 11 October 2021

Published online: 24 October 2021

(c) The Author(s) 2021 OPEN

\begin{abstract}
Abstract Guard Dog II (1969-1970) by Jean Dubuffet is an artwork that shows the characteristics of the artist's l'hourloupe period (1962-1974). This study revealed the materials and manufacturing techniques used by the artist at the time through material analysis of Guard Dog II, and suggested an appropriate conservation treatment method for the work through a cleaning test. Dust, stains, discoloration, cracks, etc. were observed on the surface of the artwork and stains were particularly severe and discoloration required conservation treatment. Prior to treatment, multiple analytical approaches such as Fourier transform infrared spectroscopy, Raman spectroscopy and gas chromatography/mass spectrometer were applied to identify the materials of the paint layers and confirm the state of the conservation of the artworks. As a result, it was confirmed that polyurethane paint was used in the artwork, and the pigment used for each color was also identified. For the stable conservation treatment of the artwork, the chromaticity, glossiness and workability of the cleaning materials were evaluated, and it was found that isopropyl alcohol and nonionic surfactant were suitable for cleaning. The conservation treatment was performed based on results from the cleaning test, and the artwork was restored cleanly. Since most of the existing research on cleaning methods has been focused on painting, this study contributes to the conservation of sculptures by suggesting cleaning methods suitable for three-dimensional colored objects.
\end{abstract}

\section{Article highlights}

- The materials and production techniques used in Jean Dubuffet, Guard Dog II were confirmed.
- As cleaning materials for deteriorated artworks, isopropyl alcohol and non-ionic surfactants are effective.

- Hydrogels are not suitable for this work due to the type and characteristics of the gels.

Keywords Painted sculpture · Paint analysis · Conservation treatment · Cleaning · Jean Dubuffet

\section{Introduction}

Since the twentieth century, various types of paints have been produced and artists have created artworks using synthetic paints on materials such as metals, wood, and plastics. Adding various colors to three-dimensional objects to create painted sculptures can further enhance their artistic and aesthetic value. Various sculptures using synthetic paints have been produced, these painted sculptures by twentieth century artists such as Alexander Calder, Niki de Saint-Phalle, Jean Dubuffet, and Roy Lichtenstein are now exhibited in museums, art galleries,

Hee Hong Kwon, entasis@korea.kr | ${ }^{1}$ Department of Conservation and Artbank, National Museum of Modern and Contemporary Art, 314 Sangdang-ro, Cheongju 28501, Republic of Korea.

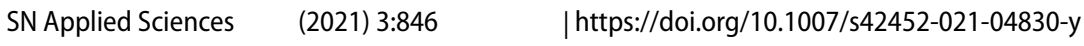


outdoor sculpture parks, around the world. Sculptures with synthetic paints started appearing in the 1960s and were produced in large numbers in the 1970 s and the 1980 s. As approximately 50 years have passed since then and therefore, many of these artworks require conservation treatment.

Since the 2000s, studies on the conservation of sculptures using synthetic paints have been conducted, with a focus on the material analysis of painted artworks and conservation treatment materials. Conservation treatments have also been performed using various techniques, such as partial repair and repainting [1-4]. Specifically, in the case of outdoor painted sculptures in severely deteriorated conditions, the method of removing the original paint layer and applying new paints is used for conservation [5-7]. In addition, Getty provided guidelines for reproducing and documenting the characteristics of the painting by reflecting the original painted sculpture as much as possible [8]. Recently, many studies have been conducted on the material analysis of synthetic paints applied to the surface of polyurethane foam artworks. Multiple analytical approaches such as SEM-EDS, FTIR and Py-GC/MS were applied to identify the materials of the paint and the cause of degradation and confirm the state of conservation of the artwork [9-11].

Various factors affect painted sculptures; these include the materials used, the keeping or exhibiting environment, and the conservation state. Therefore, it is important to secure the basic data of the sculptures to identify their characteristics and prepare an appropriate conservation method for each artwork. However, the conservation treatment of painted sculptures mainly concentrates on repainting and restoration, and few studies have investigated detailed conservation treatment methods. In particular, studies on the materials and methods used in the cleaning process have mostly focused on paintings, with only a few researching the cleaning of painted sculptures.

Currently, the National Museum of Modern and Contemporary Art in South Korea has many painted sculptures that are exhibited indoors and outdoors, based on the exhibition plans. Among them, Guard Dog II (1969-1970) by Jean Dubuffet (1901-1985) is a large work-more than $3 \mathrm{~m}$ tall-produced in 1970, with paints applied to an epoxy resin layer.

Jean Dubuffet created a new art form by rejecting traditional art and culture. In particular, he showed a shift from paintings to sculptures through a series of works called "I'hourloupe," starting in the 1960s. The l'hourloupe series goes beyond creating a distinction between paintings and sculptures and is based on three-dimensional objects breaking away from two-dimensional planes. Initially, he became interested in the industrial material polystyrene and used hot wire to cut lightweight polystyrene objects into flat and curved shapes; he then used red, blue, white, and black paint colors on these works [12]. However, polystyrene is very soft

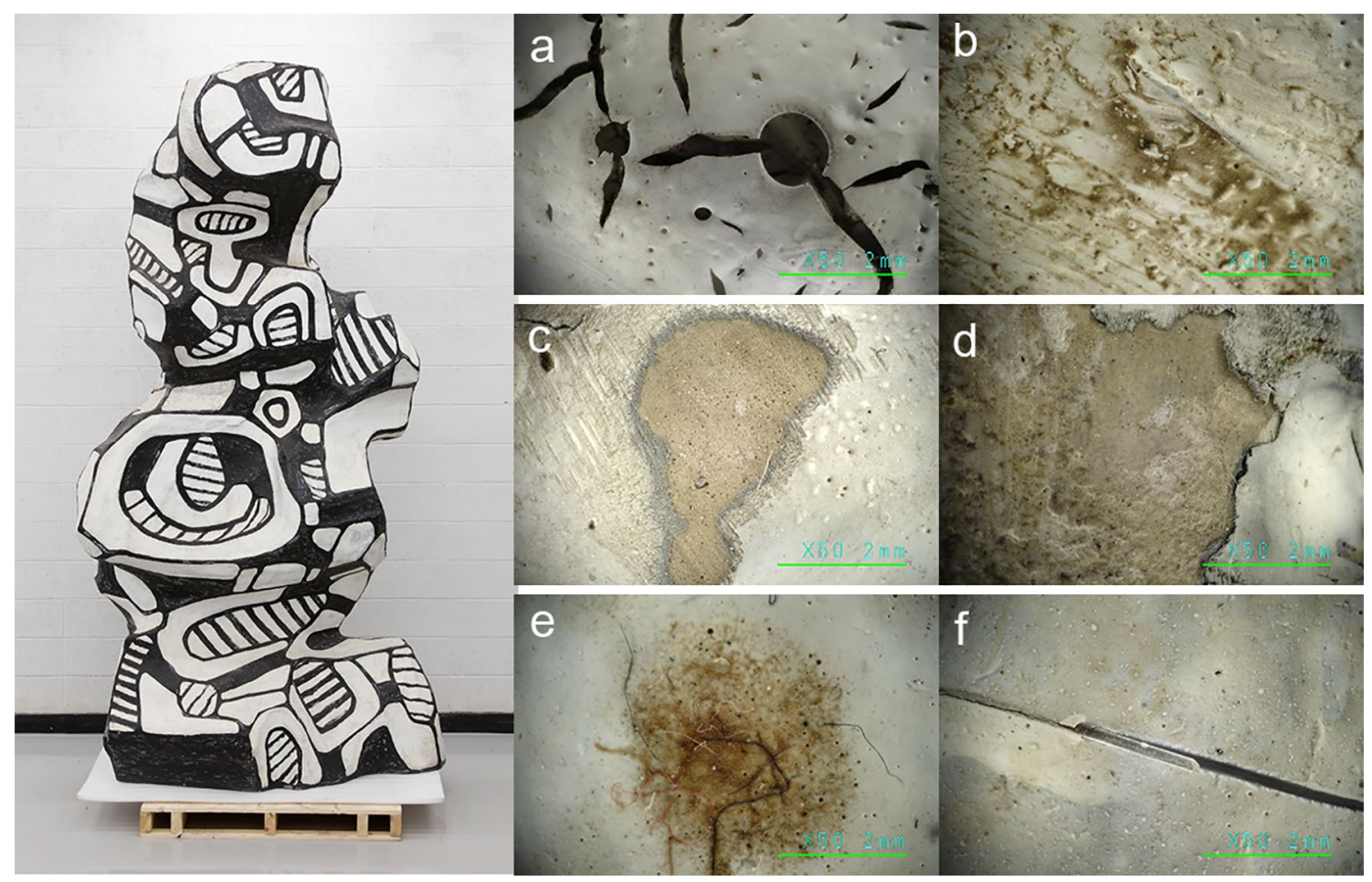

Fig. 1 Jean Dubuffet, Guard Dog Il and microscopic images of the damage (a: cracks, b: pollutants, c: abrasion, d: loss, e: foreign substance, f: brush fiber) 
and fragile and the artist therefore started investigating methods to increase its durability. As a result, he devised a "resin transfer molding."This method was to transfer the original polystyrene work into a plaster mold and then remove the polystyrene, pour polyester into the mold, and transfer it again. Because of the problem of the original work being destroyed during this process, new methods were studied and Haligon, a mold-maker, developed an epoxy resin work method that allows unlimited replication without destroying the original. From December 1967, Jean Dubuffet used both techniques together in his work [13].

Guard Dog II is coated with black and white paints, and as 50 years have passed since its creation, it needs conservation treatment due to the presence of dust, discoloration, cracks, and exfoliation on the paint surface (Fig. 1). In particular, the surface of the artwork was heavily contaminated by dust and stains, which may induce degradation, and therefore proper cleaning was required. The conservation treatment was performed based on the test results to ensure that the work was conserved and managed stably. Through scientific analysis of the paints used in the work, this study confirmed the materials originally used by the artist when producing it. Moreover, through a cleaning test of the painted sculpture, the most suitable cleaning method and materials were applied to proceed with conservation. In particular, aiming to address the paucity of studies on the appropriate cleaning materials and methods for painted sculptures, this study proposes a practical conservation method for painted works.

\section{Method}

\subsection{Paint analysis}

A sample was required to obtain information about the paint layer used in the sculpture. Fragments were collected from where the surface of the work was peeled off, and cross-sectional samples were produced using them. The samples were made one for each color (black and white). An imaging microscope (RH-2000, Hirox, Japan) was used to observe the cross-sections and measure the coating thickness of the paint layer.

The paint analysis proceeded as follows (Table 1). To estimate the pigments contained in the paints, we performed a component analysis using Raman spectroscopy (LabRAM HR, Horiba, JP) and an energy-dispersive analyzer (EDS, X-MAX, Oxford Ins., UK) mounted on a scanning electron microscope (SEM, JSM-6610LV, JEOL, JP). EDS analysis was performed by setting the acceleration voltage at $20 \mathrm{kV}$, spot size at 50, and working distance to $10 \mathrm{~mm}$, after applying a gold coating to the sample.

To analyze the organic components in the paints, we performed Fourier transform infrared spectroscopy (FTIR, Nicolet 6700, Thermo, US) with ATR (Smart orbitt, Thermo, US) to investigate the characteristics of the functional groups of the paint resins and used a gas chromatography/mass spectrometer (GC: 7890B, MS: 5977A, Agilent, US) equipped with a pyrolyzer (PY-3030S, Frontier Lab, JP) to analyse the paint components.
Table 1 Analysis methods of paints

\begin{tabular}{lll}
\hline SEM-EDS & Acceleration voltage & $20 \mathrm{kV}$ \\
\hline \multirow{3}{*}{ Raman spectroscopy } & Working distance & $10 \mathrm{~mm}$ \\
& Laser & $532 \mathrm{~nm}$ \\
& Grating & 600 (Resolution $0.33 \mathrm{~cm}^{-1} / 2400$ Grating) \\
ATR-FTIR & Scan range & $100-2000 \mathrm{~cm}^{-1}$ \\
& Scan range & $4000-400 \mathrm{~cm}^{-1}$ \\
Py-GC/MS & Resolution & $8 \mathrm{~cm}^{-1}$ \\
Pyrolyzer & & \\
& Furnace & $700{ }^{\circ} \mathrm{C}(0.2 \mathrm{~min})$ \\
GC & Interface & $320{ }^{\circ} \mathrm{C}$ \\
& Inlet & $250{ }^{\circ} \mathrm{C}$ \\
& Split ratio & $50: 1$ \\
& Column & $\mathrm{HP}-5 \mathrm{~ms}$ \\
& Gas & $\mathrm{He} 99.999 \%(1 \mathrm{ml} / \mathrm{min})$ \\
MS & Oven program & From $50{ }^{\circ} \mathrm{C}$ at $10{ }^{\circ} \mathrm{C} / \mathrm{min}$ to $300{ }^{\circ} \mathrm{C}$ \\
& Scan range & $20-500 \mathrm{~m} / \mathrm{z}$ \\
& Source & $280{ }^{\circ} \mathrm{C}$ \\
& Quadrupole & $150{ }^{\circ} \mathrm{C}$ \\
\hline
\end{tabular}




\subsection{Test for cleaning}

Tests were conducted to determine the appropriate cleaning systems for the sculpture. The suitability of cleaning materials was evaluated using organic solvents, hydrogels, and non-ionic surfactants commonly used in conservation treatments. The hydrogels were developed in the NANORESTART project [14] and Peggy $5{ }^{\circledR}$ is composed of a mixture of polyvinyl alcohol (PVA) and polyvinlypyrrolidone (PVP) polymers. It was known to be Peggy $6{ }^{\circledR}$ more flexible and resilient because it was made only with PVA [15].

The tests were performed on sections on top of the artwork. The four types of organic solvents were applied with cotton swabs to evaluate their cleaning effect. The nonionic surfactant was applied on a cotton swab to perform cleaning, after which the residual chemicals were removed by washing with deionized water. The two types of hydrogels were loaded in $20 \mathrm{wt} . \%$ ethyl alcohol and applied to the evaluation site for $20 \mathrm{~min}$ (Table 2). Appropriate cleaning materials for the artwork were selected through workability evaluations and comparison of microscopic observations (R-2000, Hirox, JP), chromaticity (CM-700d, Minolta, $\mathrm{JP}$ ), and glossiness (Micro-tri-gloss, BYK, DE) before and after cleaning.

\section{Result and discussion}

\subsection{Morphological characterization and elemental composition}

Upon observing the cross-sections of the paint samples, we found three layers: the bottom layer is white, followed by gray, and then black/white. It is considered that the painting layers are not uniform considering that each sample has a different thickness for the same color (Fig. 2).

The analysis of the pigment of the paint layer using SEM-EDS found that calcium was the main element found in the white bottom layer. In the gray layer, titanium and silicon were detected as the main components, as well as small amounts of iron and cadmium. Among the top layers, iron and silicon were detected as the main elements in the black layer. In the white layer, a noticeably high amount of titanium was detected (Fig. 3, Table 3).

\subsection{Pigment analysis in paint}

The Raman spectra showed characteristic peaks similar to those of phthalocyanine blue at 681, 1140, 1340, 1450, and $1527 \mathrm{~cm}^{-1}$ in the black paint layer (Fig. 4). As a result of analysis of the white paint layer, different results were found in the upper and lower layers. In the upper white layer, peaks estimated to be rutile-structured titanium white were observed at 444 and $608 \mathrm{~cm}^{-1}$. However, in the lower white layer, characteristic peaks similar to calcium carbonate were observed at 280 and $1086 \mathrm{~cm}^{-1}$ (Fig. 4) [16-18]. No distinct characteristic peak was found in the gray layer, and additional analysis was required.

\subsection{Analysis of organic components of paint}

The FT-IR analysis results of the white and black paints showed that the urethane $\mathrm{NH}$ stretching mode was observed at about $3300 \mathrm{~cm}^{-1}$ and the $\mathrm{CH}_{2}$ stretching deformation mode was observed at approximately 2920 and $2850 \mathrm{~cm}^{-1}$. The peak observed at $1716 \mathrm{~cm}^{-1}$ was estimated to be due to $\mathrm{C}=\mathrm{O}$ stretching [19]. Bonding related to hexamethylene diisocyanate isocyanurates (HDI) was confirmed to be around $1680 \mathrm{~cm}^{-1}$ ( $\mathrm{C}=\mathrm{O}$ stretching mode), and $1460 \mathrm{~cm}^{-1}\left(\mathrm{CH}_{2}\right.$ bending in the backbone of the $\mathrm{HDI}$ monomer). At $1515 \mathrm{~cm}^{-1}$, $-\mathrm{NH}$ deformation (urethane) and $\mathrm{C}-\mathrm{N}$ stretching vibration were found together, presumed to be polyurethane paint (Fig. 5, Table 4) [20, 21]. The peak that appears extensively near $1000 \mathrm{~cm}^{-1}$ is considered to be due to the Si-based extender pigment $[22,23]$ or it is estimated to be due to the $\mathrm{C}-\mathrm{O}-\mathrm{C}$ bond of $\mathrm{HDl}$ isocyanate [20]. However, this peak appeared at a lower position than the general $\mathrm{C}-\mathrm{O}-\mathrm{C}$ bond of $\mathrm{HDI}$.

Polyurethane is a polymer compound composed of a urethane bond (-NHCOO-), and in general, it is made by bonding an isocyanate and a polyol containing alcohol groups. Isocyanates commonly used in polyurethane manufacturing include TDI (2,4-Toluene diisocyanate), 4,4'-diphenylmethane diisocyanate (MDI), isophorone diisocyanate (IPDI), and hexamethylene diisocyanate (HDI) [24]. The paint used on the artwork showed characteristic peaks that were very similar to those of $\mathrm{HDI}$ isocyanurate.

As a result of the Py-GC/MS analysis, crotonaldehyde, benzaldehyde, benzonitrile and phthalic anhydride were found in the white paint; in particular, significant amounts of hexamethylene diisocyanate (HDI) and benzoic acid were detected. In contrast, crotonaldehyde, phenol, o-cresol, benzoic acid, phthalic anhydride, and HDI were detected in the black paint. Bisphenol $A$ was also found at approximately R.T. 19.935 (Fig. 6, Table 5).

As the HDI was confirmed in the Py-GC/MS analysis results, it is estimated that the paints used in the artwork is polyurethane based [22]. Benzaldehyde is known to be used as an additive for polyurethane paints [25], and o-cresol are components used as blocking agents for polyurethane paints [26]. Phthalic acid and benzoic acid were also detected in the analysis of polyurethane paints $[26,27]$, and bisphenol $A$ is known to improve the durability of polyurethane coatings through cross-bonding 


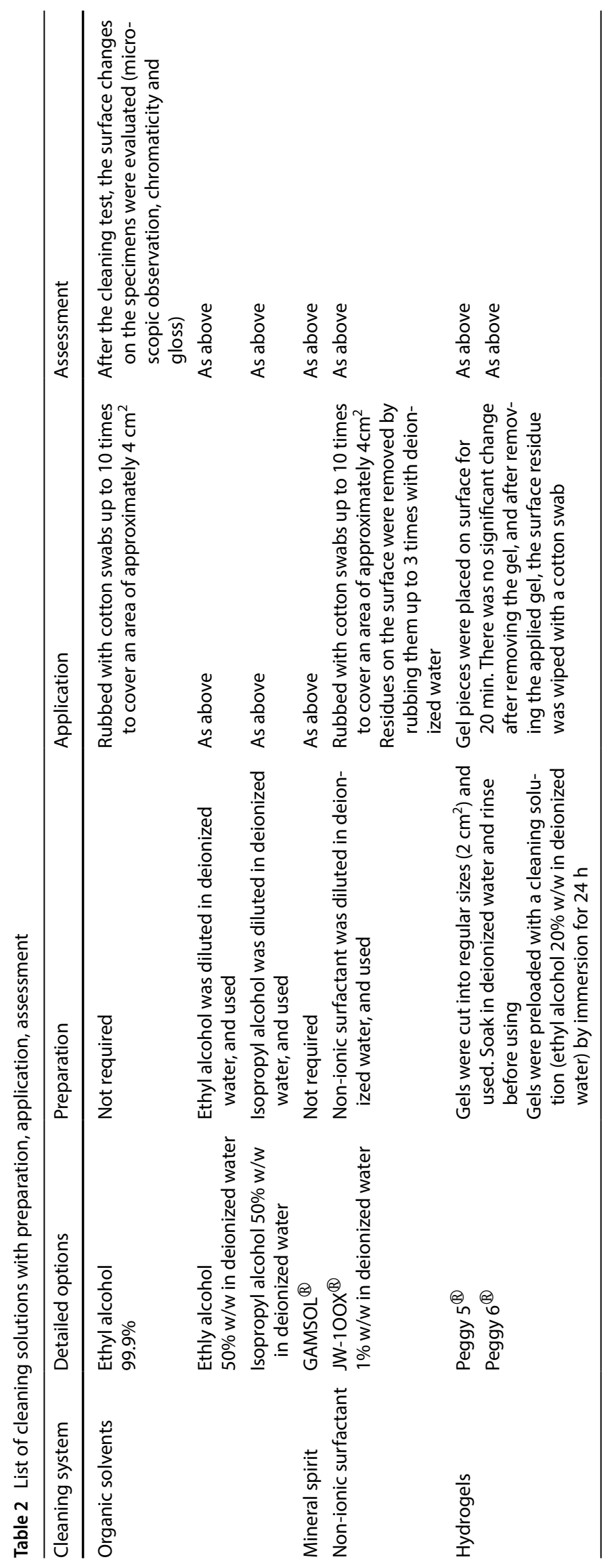



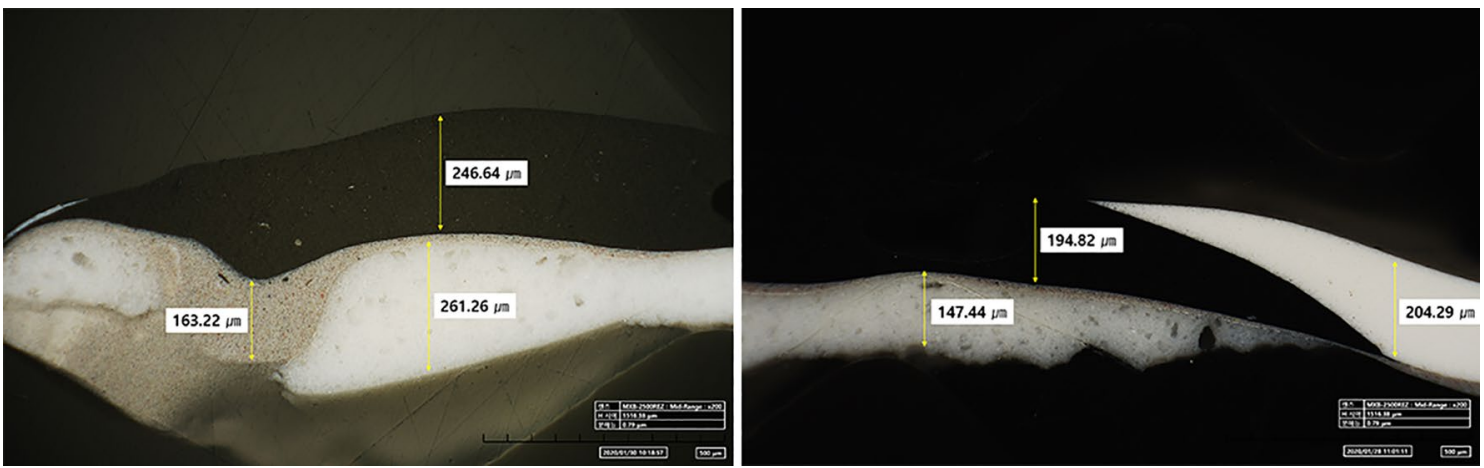

Fig. 2 Microscopic image showing a cross-section of the sample of the artwork $(\times 200)$
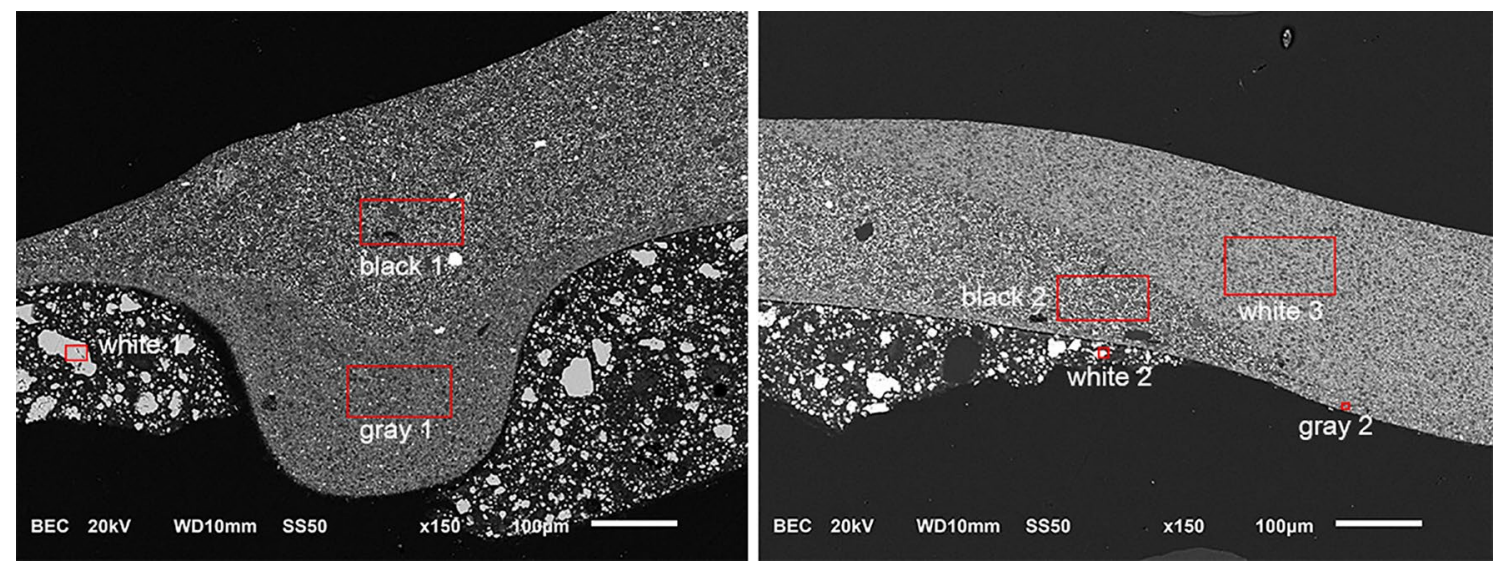

Fig. 3 Scanning electron microscope images with indication of the analyzed area $(\times 150)$

Table 3 Results of EDS

\begin{tabular}{|c|c|c|c|c|c|c|c|c|c|c|c|}
\hline & \multirow[t]{2}{*}{ Color } & \multicolumn{10}{|c|}{ Element (wt\%) } \\
\hline & & $\mathrm{C}$ & $\mathrm{O}$ & $\mathrm{Mg}$ & $\mathrm{Al}$ & $\mathrm{Si}$ & $\mathrm{Cl}$ & $\mathrm{Ca}$ & $\mathrm{Ti}$ & $\mathrm{Fe}$ & $\mathrm{Cd}$ \\
\hline \multirow[t]{2}{*}{ Putty } & White 1 & 19.30 & 52.2 & 0.16 & - & 0.07 & - & 28.02 & 0.15 & 0.10 & - \\
\hline & White 2 & 22.69 & 50.13 & 0.15 & - & 0.11 & - & 26.62 & 0.10 & 0.19 & - \\
\hline \multirow[t]{2}{*}{ Primer } & Gray 1 & 44.85 & 38.58 & - & 0.14 & 6.06 & - & - & 8.44 & 0.79 & 0.76 \\
\hline & Gray 2 & 45.93 & 38.66 & - & 0.15 & 5.58 & - & - & 8.17 & 0.71 & 0.81 \\
\hline \multirow[t]{3}{*}{ Base coat } & Black 1 & 46.26 & 33.94 & - & - & 4.98 & 0.08 & - & - & 8.81 & - \\
\hline & Black 2 & 51.84 & 34.95 & - & - & 5.37 & - & 0.02 & 0.09 & 7.72 & - \\
\hline & White 3 & 42.51 & 39.89 & - & 0.24 & 5.57 & - & 0.08 & 11.71 & - & - \\
\hline
\end{tabular}

with polyisocyanate [27]. In the case of crotonaldehyde, there is a case of detection in off-gases of polyurethane [28].

Through the artist's other works and art brochures, it is known that Jean Dubuffet used matte polyurethane paints to create artworks [13, 29, 30]; this was confirmed by the analysis. Polyurethane paints seemed to have been used in the arts as the polyurethane industry expanded in the 1960s. In fact, it has been reported that polyurethane paints have been used in many outdoor artworks in the late twentieth century $[1,20]$.

As a result of SEM-EDS analysis of the paint used in the artwork, it was classified into three layers. The lower white layer had relatively large and irregular particles compared to the upper white layer, and calcium was detected as a main component. This was confirmed by the Raman analysis result as calcium carbonate, and this layer is thought to be the putty (or first primer) used to smooth the surface of

\section{SN Applied Sciences}



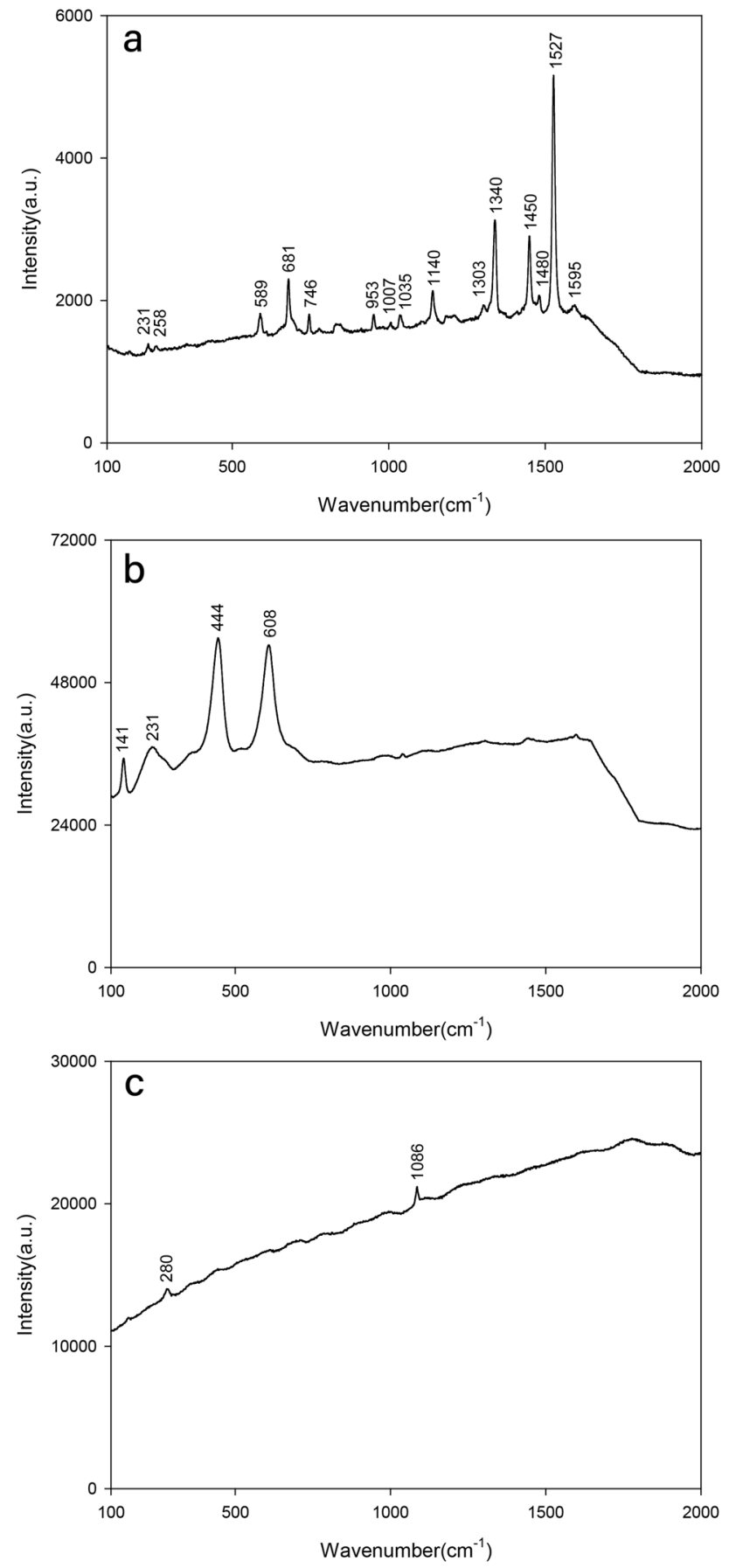

Fig. 4 Raman spectrum of paints (a: black basecoat, b: white basecoat, c: white putty)

the work [31]. The gray layer is considered to be a primer surfacer to maximize the appearance and performance of the basecoat and to even out the surface, as it is located under the top coat layer [32]. Ti was identified as the main component in the gray layer, and it is assumed that titanium white was used. Also, Fe and Cd were detected, indicating that a small amount of iron oxide and cadmium pigment were mixed together. The detection of Si can appear to be due to the use of silicone as an extender for paints in general $[10,33]$. The white and black layers of the uppermost layer represent the color of the artwork as a basecoat. The upper white layer containing $\mathrm{Ti}$ as a main component was confirmed to be titanium dioxide (rutile) as a result of Raman analysis. In the black layer, the detection of Fe is presumed to be associated with iron oxide and Prussian blue [34]. As a result of Raman analysis, a peak of phthalocyanine blue was detected, but iron oxide and Prussian blue were not confirmed. It is considered that there is a limit to the peak detection of the pigment due to the various components mixed in the paint. However, it is presumed that these pigments were used because black can be produced when the warm color of iron oxide and the blue color of phthalocyanine blue and Prussian blue are mixed together.

\subsection{Test for cleaning}

The results of microscopic observations before and after cleaning showed superiority of cleaning effects in the following order: hydrogels 1 and $2<$ mineral spirit $<99.5 \%$ ethyl alcohol $<50 \mathrm{wt} \%$ ethyl alcohol $<50 \mathrm{wt} \%$ isopropyl alcohol $\approx 1$ wt. $\%$ non-ionic surfactant. The $50 \mathrm{wt} . \%$ isopropyl alcohol and $1 \mathrm{wt} . \%$ non-ionic surfactant solutions easily removed the pollutants, and compared to these, the $99.5 \%$ ethyl alcohol and mineral spirit did not completely remove the pollutants. Regarding the hydrogels, the pollutants were not absorbed by the gels, showing almost no cleaning effect, and the pollutants could be removed only when they were wiped with a cotton swab after removing the coated gels (Table 6).

The color difference comparison results showed that when isopropyl alcohol and a non-ionic surfactant were used, the color difference (Lab*) was 6 or higher, showing definite changes. In the case of the $99.5 \%$ ethyl alcohol solution, the color difference was less than 3 . After using the hydrogels, the color difference was between 4 and 6 ; however, it was not the effect of the gels themselves, as the effect was obtained by wiping with a cotton swab after removing the hydrogels (Fig. 7a).

The glossiness measurement results showed a glossiness of less than $10 \mathrm{GU}$ (Gloss unit), confirming that the surface was matte. Similar to the results of the color difference analysis, $50 \mathrm{wt} \%$ isopropyl alcohol and $1 \mathrm{wt} \%$ nonionic surfactant showed significant glossiness changes among the solvents, except for the two types of hydrogels. However, as the change in glossiness was less than $3 \mathrm{GU}$ overall, the change in glossiness before and after cleaning was insignificant (Fig. 7b).

The pollutant removal results and workability varied depending on the solvent type; the types were compared 
Fig. 5 IR spectrum of white and black paint
Table 4 IR band position of paint samples and their assignment
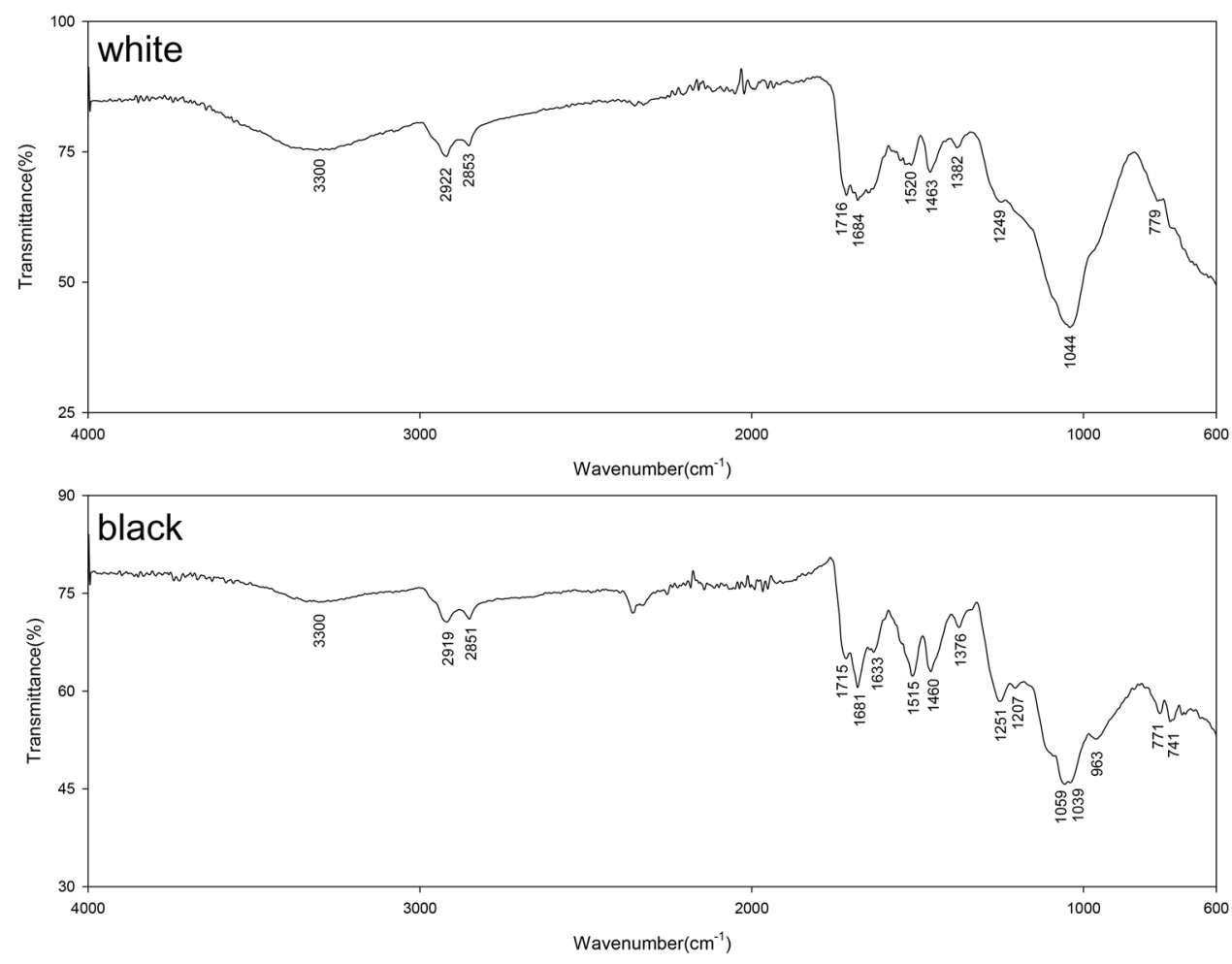

\begin{tabular}{|c|c|c|}
\hline \multicolumn{2}{|c|}{ Wave number $\left(\mathrm{cm}^{-1}\right)$} & \multirow[t]{2}{*}{ Assignment } \\
\hline White & Black & \\
\hline 3300 & 3300 & $\begin{array}{l}\text { Secondary urethane } \mathrm{N}=\mathrm{H} \text { stretch/NH bonded/N-H } \\
\text { stretching vibration band }\end{array}$ \\
\hline 2922 & 2919 & va $\mathrm{CH}_{2}$ \\
\hline 2853 & 2851 & vs $\mathrm{CH}_{2}$ \\
\hline 1716 & 1715 & $\mathrm{H}$ bond $\mathrm{C}=\mathrm{O}$ stretch \\
\hline 1684 & 1681 & $\mathrm{H}$ bond $\mathrm{C}=\mathrm{O}$ stretch/tertiary urethane $\mathrm{C}=\mathrm{O} / \mathrm{C}=\mathrm{O}$ bonded \\
\hline- & 1633 & Carbonyl groups in urea bonds $(\mathrm{C}=\mathrm{O})$ \\
\hline 1520 & 1515 & $\delta-\mathrm{NH}$ and va $\mathrm{C}-\mathrm{N}$ \\
\hline 1463 & 1460 & $\delta-\mathrm{CH}_{2}$ \\
\hline 1382 & 1376 & $\delta-\mathrm{C}\left(\mathrm{CH}_{3}\right)$ \\
\hline 1249 & 1251 & $(\mathrm{O}=) \mathrm{C}-\mathrm{O}-\mathrm{C}$ stretch/urethane $\mathrm{C}-\mathrm{O}$ stretch \\
\hline 1044 & $1059-1039$ & $\mathrm{Si}-\mathrm{O}-\mathrm{Si}$ \\
\hline 779 & 771 & C-N skeletal stretch \\
\hline
\end{tabular}

and evaluated numerically. Considering ethyl alcohol, no significant change was observed overall when removing pollutants and they could be removed only by applying more force, compared with the case of isopropyl alcohol. The 50 wt\% ethyl alcohol solution had relatively lower volatility, and a change was observed when it was washed and then wiped with a dry cloth. In the case of $50 \mathrm{wt} \%$ isopropyl alcohol, it was easy to remove the pollutants and it took relatively less time to process, because the volatility of the solvent was high. The mineral spirit showed a lower pollutant removal effectiveness, compared with other materials, and did not show significant overall changes. Meanwhile, 1 wt\% non-ionic surfactant easily removed the pollutants, but washing with distilled water was required after using the solvent. The hydrogels were not suitable for the artwork because they showed virtually no cleaning effect (Fig. 7c).

Gel systems are usually applied to flat artworks, such as oil paintings and paper canvas, because their stability and workability for artworks are superior and their toxicity 
Fig. 6 Pyrograms of white (a: benzoic acid, $\mathbf{b}$ : hexamethylene diisocyanate) and black paint (a: phthalic anhydride, b: hexamethylene diisocyanate, $\mathbf{c}$ : bisphenol A)
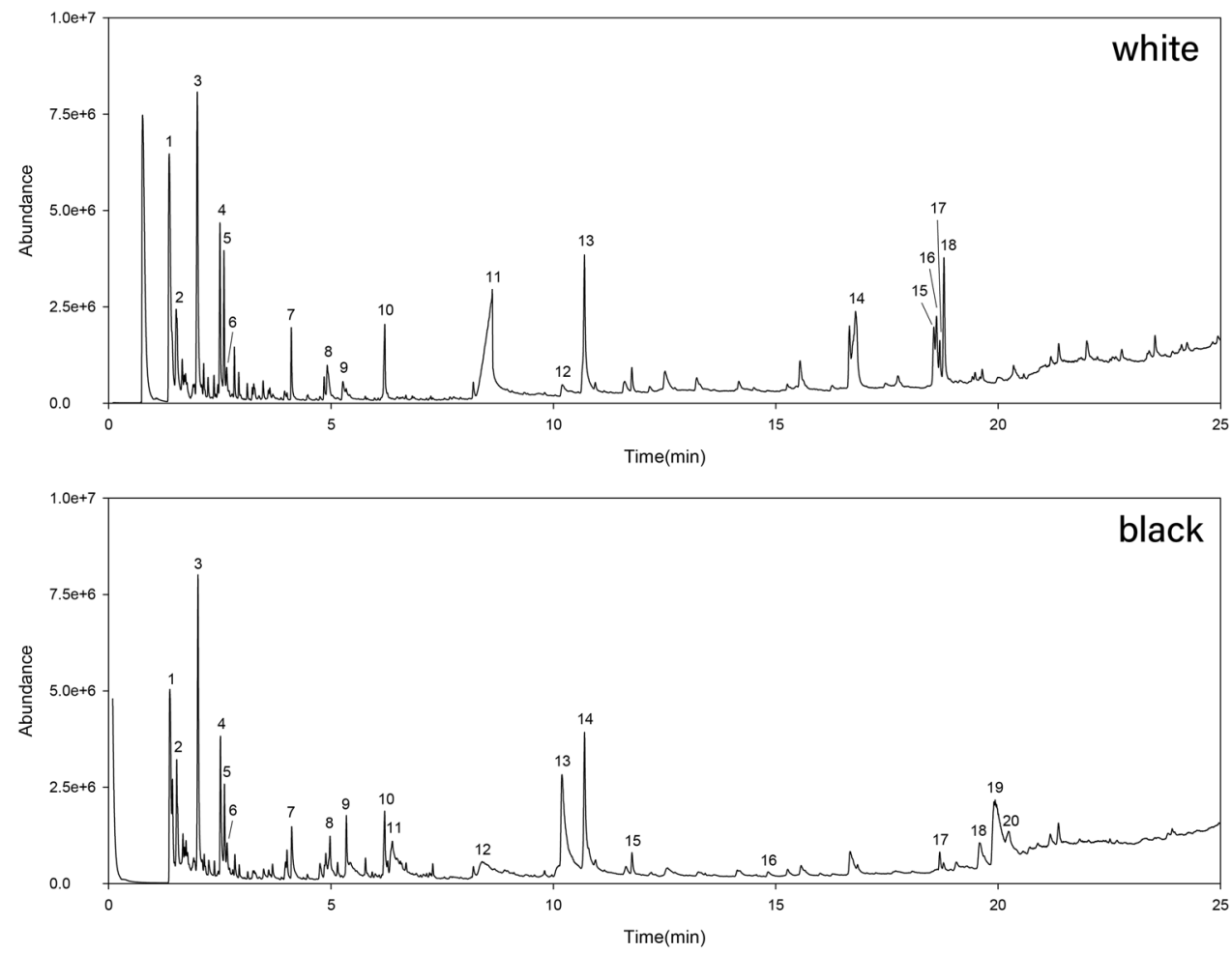

Table 5 Compounds identified in white paint(left) and black paint(right)

\begin{tabular}{|c|c|c|c|c|c|}
\hline $\begin{array}{l}\text { R.T } \\
(\mathrm{min})\end{array}$ & Compounds & Main ions(m/z) & $\begin{array}{l}\text { R.T } \\
(\mathrm{min})\end{array}$ & Compounds & Main ions(m/z) \\
\hline 1 & 2-Methyl-1-butene & $55,70,39$ & 1 & 2-Methyl-1-butene & $55,70,39$ \\
\hline 2 & Crotonaldehyde & $70,41,39$ & 2 & Crotonaldehyde & $70,41,39$ \\
\hline 3 & 2-Methyl-2-butenal & $84,55,39,78$ & 3 & 2-Methyl-2-butenal & $84,55,78,39$ \\
\hline 4 & Octenol & $57,71,29,41$ & 4 & Octenol & $57,29,41,71$ \\
\hline 5 & 1-Undecene & $41,83,69,98$ & 5 & 1-Pentadecene & $41,83,69,39$ \\
\hline 6 & Toluene & 91,92 & 6 & Toluene & 91,92 \\
\hline 7 & Hydroxyacetone & $43,72,59,31$ & 7 & Hydroxyacetone & $43,72,59$ \\
\hline 8 & Benzaldehyde & $105,106,77,51$ & 8 & Isopropylbenzene & $105,120,106,77$ \\
\hline 9 & Benzonitrile & $103,76,50$ & 9 & Isopropylbenzene & $105,120,106,77$ \\
\hline 10 & Octenol & $57,71,29,86,41$ & 10 & Octenol & $57,71,29,86$ \\
\hline 11 & Benzoic acid & $105,122,77,51$ & 11 & o-Cresol & $108,107,79,77$ \\
\hline 12 & Phthalic anhydride & $104,76,50,148$ & 12 & Benzoic acid & 105,77 \\
\hline 13 & Hexamethylene diisocyanate & $56,41,85,99,98$ & 13 & Phthalic anhydride & $104,76,50,148$ \\
\hline 14 & 2-Heptadecanone & $58,43,59,71$ & 14 & Hexamethylene diisocyanate & $56,41,85,99,98$ \\
\hline 15 & Octadecanal & $43,71,55,96,82$ & 15 & Benzoic acid & 105,77 \\
\hline 16 & Octadecanal & $43,71,55,96,97$ & 16 & Diethyl phthalate & $149,105,133$ \\
\hline 17 & Diisononyl phthalate & $149,69,41$ & 17 & Diisononyl phthalate & $149,69,41$ \\
\hline \multirow[t]{3}{*}{18} & 2-Nonadecanone & $58,59,43,71$ & 18 & Diisononyl phthalate & $149,86,150$ \\
\hline & & & 19 & Bisphenol A & $213,228,119,214$ \\
\hline & & & 20 & Bisphenol A & $213,228,119,214$ \\
\hline
\end{tabular}


Table 6 Microscopic observations before and after cleaning tests

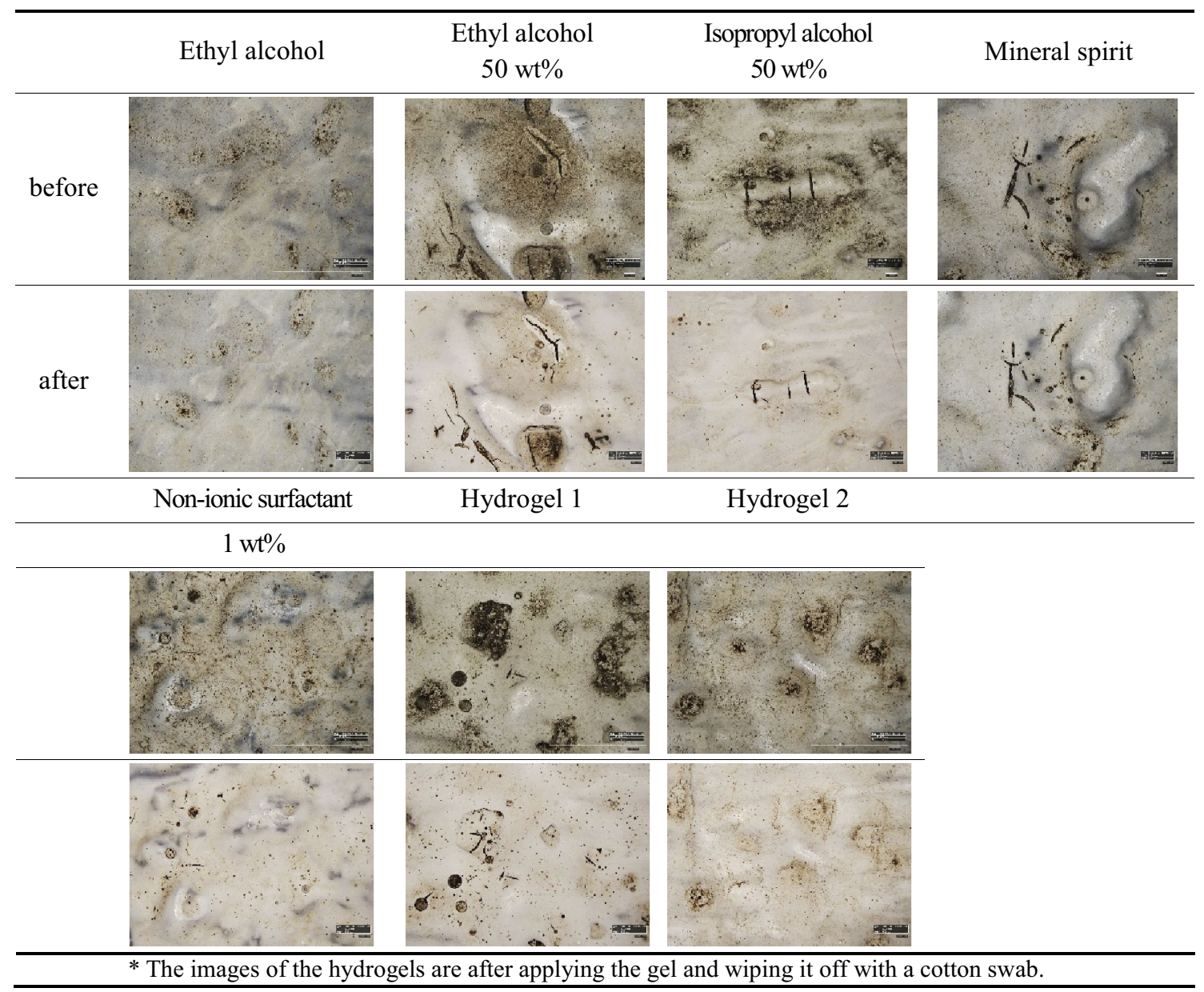

is lower, compared with conventional cleaning methods [35-37]. And research on the applicability of objects and three-dimensional parts of artworks has been conducted [38, 39].

However, no cleaning effect could be seen on this artwork. It is thought that the surface was not smooth and had many irregularities, and that the gels were not attached to the three-dimensional artwork, so the cleaning effect was not significant. The effect of the gels has different characteristics such as flexibility and strength depending on the type of gel, and it seems to be affected by the correlation between the material and the gel used in the artwork [40]. Therefore, it is considered that the method of using the gel applied in this test was not suitable for the artwork, and it is judged that it is necessary to study the type and method of the gel that can be applied to synthetic paints in the future.

\subsection{Conservation treatment}

Based on the results of the cleaning solvent tests, cleaning was performed. A non-ionic surfactant was used for first-phase cleaning; this removed pollutants from the entire surface. Isopropyl alcohol was used for secondphase cleaning to remove the yellowish parts, severely polluted parts, and parts with scribbling and foreign substances that remained after the first cleaning phase. It was washed twice or thrice with deionized water to minimize residue. This had to be performed delicately because the surface was uneven and the paint layer had been weakened by degradation. Due to the physical size of the sculpture, the cleaning process took about five months. After cleaning, a one-component urethane coating was injected into the partially cracked and lifted parts of the paint layer to reinforce the paint layer of the artwork. Through color and glossiness comparisons before and after the conservation treatment, we confirmed that the treatment was performed stably. In particular, it was confirmed that the color difference in the yellowed parts before and after cleaning was 14 or higher, and the aesthetic value could be recovered through cleaning (Figs. 8, 9, 10; Table 7). Also, fifty years have passed since the work was created, but information on the color used in the work could not be confirmed. 
Fig. 7 Result of the cleaning test (a: color difference, $\mathbf{b}$ : gloss, c: workability [0 -5 points given, depending on the cleaning effect]) a

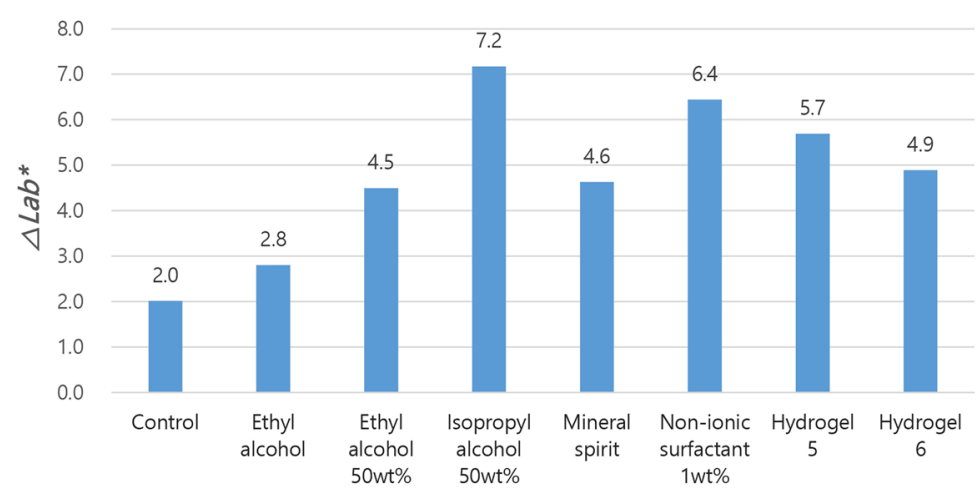

b

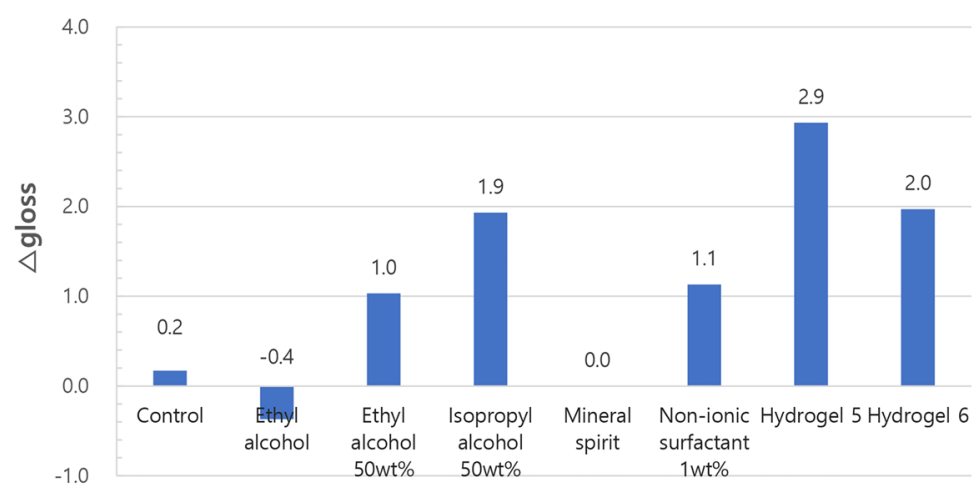

C

\section{Workability}

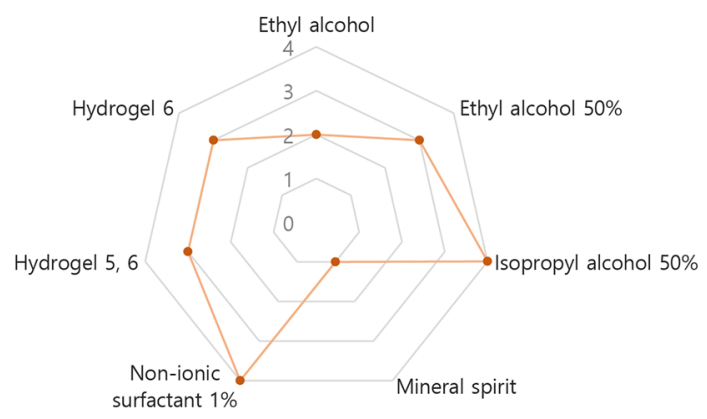



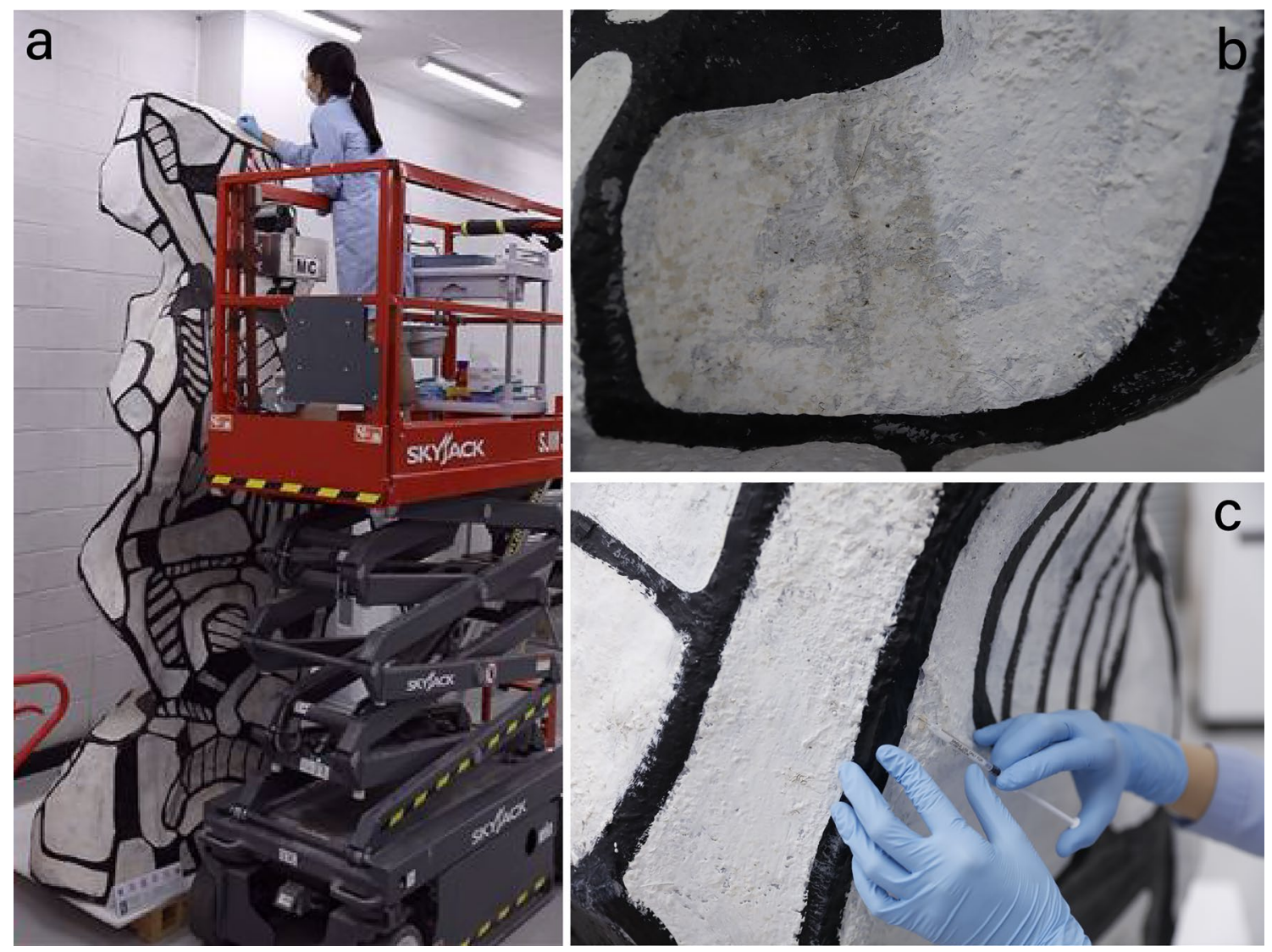

Fig. 8 a A conservator cleans Guard Dog II, b before and after cleaning, c reinforcement treatment of cracks

Fig. 9 Detail of Guard Dog II (left: before treatment, right: after treatment)

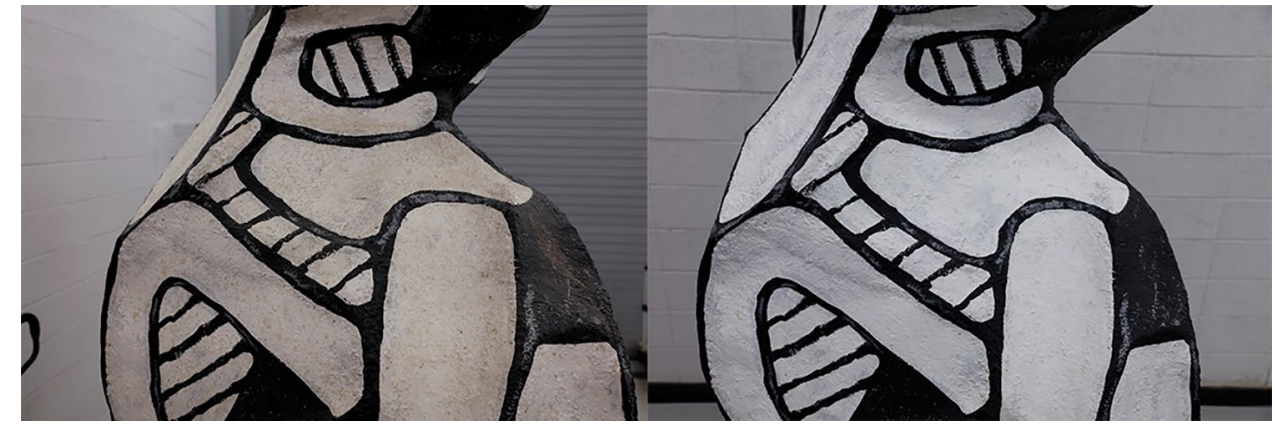




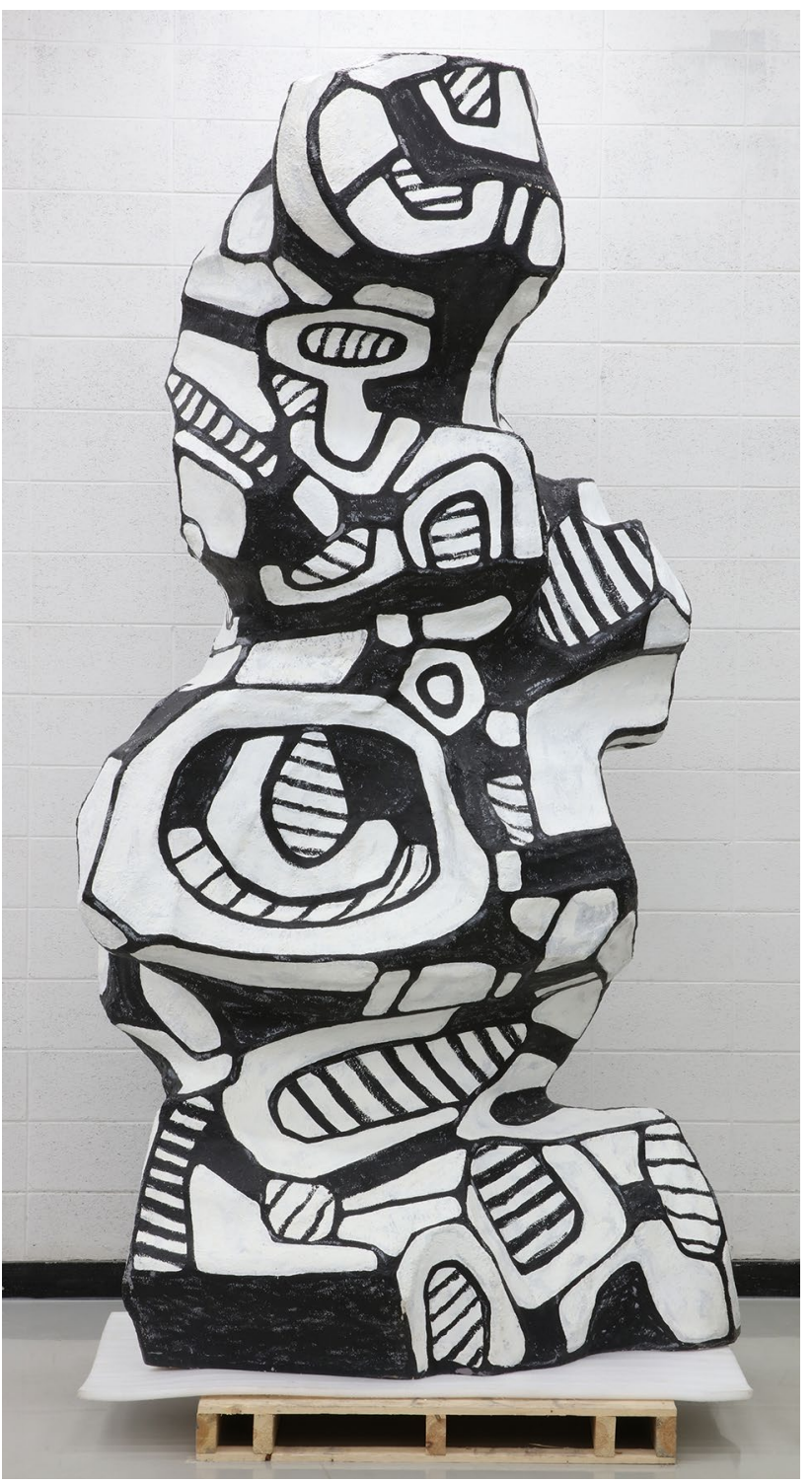

Fig. 10 Condition of Guard Dog II after treatment

Table 7 Color comparison before and after treatment

\begin{tabular}{lrrrr}
\hline & White & Black & Gray & Yellowing \\
\hline Before & & & & \\
$L$ & 90.43 & 24.86 & 50.48 & 77.16 \\
$a$ & -0.93 & 0.39 & -0.09 & 0.62 \\
$b$ & 6.30 & -0.68 & 0.11 & 14.50 \\
After & & & & \\
$L$ & 91.49 & 24.31 & 49.28 & 87.78 \\
$a$ & -0.88 & 0.40 & -1.46 & -0.78 \\
$b$ & 3.34 & -0.75 & -2.43 & 5.12 \\
Color difference & & & & \\
Lab* & 3.14 & 0.56 & 3.12 & 14.24 \\
\hline
\end{tabular}

Through this process, it was meaningful to be able to understand the color of the work.

\section{Conclusion}

The aim of this study was to analyze the paints used in Jean Dubuffet's 'Guard Dog II' and to suggest materials and methods for stable cleaning in the artwork. As result of the multiple analyses, FT-IR and Py-GC/MS analysis confirmed the type of paint used in the work, and the pigments used in each paint could be estimated through SEM-EDS and Raman analysis.

Considering the characteristics of the artwork, an efficient conservation treatment method was required because it was large (more than $3 \mathrm{~m}$ high) and the surface was not smooth. Accordingly, a cleaning test was performed by applying organic solvents commonly used in conservation treatment and hydrogels that have recently been used as cleaning materials. The results showed that $50 \mathrm{wt} \%$ isopropyl alcohol and $1 \mathrm{wt} \%$ non-ionic surfactants were the most effective. Hydrogels were expected to be effective because of their currently known characteristics; however, they were found to be unsuitable for artworks with uneven surfaces, such as Guard Dog II. Research on hydrogels continues to develop, and studies on the applicability of gels to modern oil paints and modern synthetic paints are in progress $[15,40]$. However, as hydrogels have various types and characteristics depending on the manufacturing method, it is thought that research on the relationship between each artwork and material is necessary.

Conservation treatment was carried out based on the results of the cleaning test, and the artwork was stably conserved through cleaning and strengthening treatment of the surface of the work. Most previous research on cleaning methods has focused on paintings. However, this study will provide effective information on the conservation of three-dimensional objects by suggesting a suitable cleaning method for synthetic painted sculptures.

Acknowledgements The research was made possible by the National Museum of Contemporary Art in Korea(MMCA). We are grateful for MMCA's support.

Authors' contribution $\mathrm{YB}$ and $\mathrm{HH}$ provided support and guidance for this study. YB performed all the experiments and conservation treatment and wrote the first draft of the manuscript. NR performed the analysis of paints and interpreted the data. YM and JA supported the basic investigation and cleaning of the artwork. SM contributed to the conservation treatment. $\mathrm{HH}$ reviewed the manuscript. All authors have read and approved the final manuscript.

Funding Not applicable. 
Availability of data and materials All data are available from the corresponding author upon reasonable request.

Code availability Not applicable.

\section{Declarations}

Conflict of interest The authors declare that they have no conflict of interests.

Ethics approval Not applicable.

Consent to participate Not applicable.

Consent for publication Not applicable.

Open Access This article is licensed under a Creative Commons Attribution 4.0 International License, which permits use, sharing, adaptation, distribution and reproduction in any medium or format, as long as you give appropriate credit to the original author(s) and the source, provide a link to the Creative Commons licence, and indicate if changes were made. The images or other third party material in this article are included in the article's Creative Commons licence, unless indicated otherwise in a credit line to the material. If material is not included in the article's Creative Commons licence and your intended use is not permitted by statutory regulation or exceeds the permitted use, you will need to obtain permission directly from the copyright holder. To view a copy of this licence, visit http://creativecommons. org/licenses/by/4.0/.

\section{References}

1. Beerkens L, LearnerT (2014) Conserving outdoor painted sculpture: proceedings from the interim meeting of the modern materials and contemporary art working group of ICOM-CC. The Getty Conservation Institute, Los Angeles. ISBN: 9781937433215

2. Considine B, Wolfe J, Posner K, Bouchard M (2010) Conserving outdoor sculpture: the stark collection at the Getty Center. Getty publications, Los Angeles

3. Escarsega JA, Mack A, Rivenc R, Learner T (2016) Coat of arms: dovetailing the needs of outdoor sculpture and military assets to develop more durable and adaptable paint systems. Stud Conserv 61:49-54. https://doi.org/10.1080/00393630.2016. 1196431

4. Kwon HH, Kim JH, Han YB (2016) A study on conservation of outdoor painted sculptures: Niki de Saint-Phalles "Black Nana." J Conserv Sci 32:333-343. https://doi.org/10.12654/JCS.2016. 32.3.04

5. Lew NN, Choi JH (2016) New paint, new challenges: conservation of Roy Lichtenstein's outdoor sculpture House I. Stud Conserv 61:114-119. https://doi.org/10.1080/00393630.2016.11946 90

6. Wolfe J (2014) Three brushstrokes: re-creating Roy Lichtenstein's early techniques for outdoor painted sculpture. In: Beerkens $L$, Learner T (eds) Conserving outdoor painted sculpture: proceedings from the interim meeting of the modern materials and contemporary art working group of ICOM-CC. The Getty Conservation Institute, Los Angeles, pp 43-53. ISBN: 9781937433215

7. Beerkens L, Tajiri RV (2014) As good as new: On the recoating of Shinkichi Tajiri's Square Knot (1974) in Venlo, the Netherlands. In: Beerkens L, Learner T (eds) Conserving outdoor painted sculpture: proceedings from the interim meeting of the modern materials and contemporary art working group of ICOM-CC. The Getty Conservation Institute, Los Angeles, pp 23-31. ISBN: 9781937433215

8. Langenbacher J, Rivenc R and Flavin A (2017) Documenting painted surfaces for outdoor painted sculptures: a manual of laboratory and field test methods. The Getty conservation Institute, Los Angeles. ISBN: 9781937433215

9. Nasa LJ, Biale G, Sabatini F, Degano I, Colombini PM, Modugno F (2019) Synthetic materials in art: a new comprehensive approach for the characterization of multi-material artworks by analytical pyrolysis. Herit Sci 7:1-14. https://doi.org/10.1186/ s40494-019-0251-4

10. Macro N, loele M, Brevi M, Scicolone G, Lazzari M (2020) New insight on the oxidative degradation in materials used by Piero Gilardi in two second generation Nature Carpets: a micro-invasive spectroscopic approach. J Cul Herit 46:278-282. https://doi. org/10.1016/j.culher.2020.07.003

11. Zuena $M$, Legnaioli $S$, Campanella $B$, Palleschi V, Tomasin $P$, Tufano KM, Modugno F, Nasa LJ, Nodari L (2020) Landing on the moon 50 years later: A multi-analytical investigation on Superficie Lunare (1969) by Giulio Turcato. Microchem J 157:1-9. https://doi.org/10.1016/j.micro.2020.105045

12. Kim SH (2014) The "artistic creation" and "sculpture" of Jean Dubuffet-around "Group of four trees" and "Boiler with chimney." Kor J Art Media 13:86-102

13. Dubuffet J (2011) Jean Dubuffet: writings on sculpture. Richter Verlag, Dusseldorf, pp 153-60. ISBN: 9783941263185

14. Center for Colloid and Surface Science(CSGI) (2018) NANOmaterials for the REStoration of works of ART. https://cordis.europa. eu/project/id/646063

15. Bartoletti A, Maor T, Chelazzi D, Bonelli N, Baglioni P, Angelova LV, Ormsby B (2020) Facilitating the conservation treatment of Eva Hesse's Addendum through practice based research, including a comparative evaluation of novel cleaning systems. Herit Sci 8:6-11. https://doi.org/10.1186/s40494-020-00378-z

16. Caggiani MC, Cosentino A, Mangone A (2016) Pigments checker version 3.0, a handy set for conservation scientists: a free online Raman spectra database. Microchem J 129:123-132. https://doi. org/10.1016/j.micoc.2016.06.020

17. Balachandran UG, Eror NG (1982) Raman spectra of titanium dioxide. J Sol St Chem 42:276-282. https://doi.org/10.1016/ 0022-4596(82)90006-8

18. Harroun SG, Bergman J, Jablonski E, Brosseau CL (2011) Surfaceenhanced Raman spectroscopy analysis of house paint and wallpaper samples from an 18th century historic property. Analyst 136:3453-3460. https://doi.org/10.1039/c0an00832j

19. Kaminski AM, Urban MW (1997) Interfacial studies of crosslinked polyurethanes; part I. Quantitative and structural aspects of crosslinking near film-air and film-substrate interfaces in solvent-borne polyurethanes. J Coat Technol 69(872):55-66. https://doi.org/10.1007/BF02696244

20. Defeyt C, Langenbache J, Rivenc R (2017) Polyurethane coatings used in twentieth century outdoor painted sculptures. Part I: comparative study of various systems by means of ATRFTIR spectroscopy. Herit Sci 5:1-11. https://doi.org/10.1186/ s40494-017-0124-7

21. Zhang Y, Maxted J, Barber A, Lowe C, Smith R (2013) The durability of clear polyurethane coil coatings studied by FTIR peak fitting. Polym Degrad Stabil 98:527-534. https://doi.org/10.1016/j. polymdegradstab.2012.12.003

22. Learner TJS (2004) Analysis of modern paints. Getty publications, Los Angeles

23. Meyers RA (2000) Encyclopedia of analytical chemistry: Applications, Theory, and Instrumentation. Wiley, New york 
24. Larson EA, Lee J, Pailson A, Lee YJ (2019) Structural analysis of polyurethane monomers by pyrolysis GC TOFMS via dopantassisted atmospheric pressure chemical ionization. J Am Soc Mass Spectrom 30:1046-1058. https://doi.org/10.1007/ s13361-019-02165-y

25. Allauddin S, Jean KK, Mishra AK, Radhika KR, Narayan R, Raju KVSN (2012) Synthesis \& characterization of benzaldehyde modified acetoacetylated polyesters for polyurethane/urea coatings. Prog Org Coat 75(1-2):131-138. https://doi.org/10.1016/j.porgc oat.2012.04.008

26. Kwon SK, Park NJ, Nam YK (1997) A study on the effects of various reaction conditions on the blocking reactions of TDI and $\mathrm{MDI}$ in the preparation of polyurethane varnishes. $J$ Ind Eng Chem 8(2):308-314

27. Defeyt C, Schilling M, Langenbacher J, Escarsega J, Rivenc R (2017) Polyurethane coatings in twentieth century outdoor painted sculptures. Part II: Comparative study of four systems by means of Py-GC/MS. Herit Sci 5:1-9. https://doi.org/10.1186/ s40494-017-0129-2

28. Krzymien ME (1989) GC-MS analysis of organic vapours emitted from polyurethane foam insulation. Int J Environ Anal Chem 36(4):193-207. https://doi.org/10.1080/03067318908026873

29. Breder F (2014) Preserving artistic style and authentic appearance in hand-painted outdoor sculptures. In: Beerkens L, Learner $\mathrm{T}$ (eds) Conserving outdoor painted sculpture: proceedings from the interim meeting of the modern materials and contemporary art working group of ICOM-CC. The Getty Conservation Institute, Los angeles, pp 65-71. ISBN: 9781937433215

30. Abadie D (2011) Dubuffet as architect. Editions Hazan, Paris

31. Kang HS, Kim SH, Park MS (2016) Characteristic analysis of paint used in defense industries equipments of Korean conflict in the war memorial of Korea. J Conserv Sci 32(2):217-219. https://doi. org/10.12654/JCS.2016.32.2.10

32. Gelder JD, Vandenabeele P, Govaert F, Moens L (2005) Forensic analysis of automotive paints by Raman spectroscopy. J Raman Spectrosc 36:1059-1060. https://doi.org/10.1002/JRS.1408

33. Braod R, Power G, Sonego A (1993) Extender pigment. In: Oil and Colour Chemist's Association (ed), Surface coatings. Springer, Netherlands, pp 514-529
34. Lizun D (2020) A preliminary study of Liu Kang's palette and the discovery and interpretation of hidden paint layers. Heri Sci 8:1-18. https://doi.org/10.1186/s40494-020-0363-x

35. Domingues J, Bonelli N, Giorgi R, Fratini E, Baglioni P (2013) Innovative method for the cleaning of water-sensitive artifacts: synthesis and application of highly retentive chemical hydrogels. Int J Conserv Sci 4:715-722

36. Baglioni M, Alterini M, Giorgi R, Shashoua Y, Brajer I and Baglioni P (2017) Nanofluids confined in chemical hydrogels for the selective removal of graffiti from street art. In: ICOM-CC 18th triennial conference, modern materials and contemporary art. Copenhagen, pp 1-7

37. Giorgi R, Baglioni M, Baglioni P (2017) Nanofluids and chemical highly retentive hydrogels for controlled and selective removal of overpaintings and undesired graffiti from street art. Anal Bioanal Chem 409:3707-3712. https://doi.org/10.1007/ s00216-017-0357-z

38. Sansonetti A, Casati M, Striova J, Canevali C, Anzani M, Rabbolini A (2012) A cleaning method based on the use of agar gels: new tests and perspectives. In: 12th International congress on the deterioration and conservation of stone, New York, pp 1-13

39. Carretti E, Giorgi R (2013) Cleaning IV: applications and cased studies. In: Baglioni P, Chelazzi D (eds) Nanoscience for the conservation of works of art. RSC Publishing, London, pp 280-303. https://doi.org/10.1039/9781849737630-00280

40. Mastrangeloa R, Chelazzia D, Poggia G, Fratinia E, Buemic LP, Petruzzellisc ML, Baglionia P (2020) Twin-chain polymer hydrogels based on poly(vinyl alcohol) as new advanced tool for the cleaning of modern and contemporary art. Proc Natl Acad Sci USA 117:7011-7020. https://doi.org/10.1073/pnas.1911811117

Publisher's Note Springer Nature remains neutral with regard to jurisdictional claims in published maps and institutional affiliations. 